\title{
Teknolojik Bir Yaklaşım: Sanal Gerçeklik Maruz Bırakma Terapisi
}

Bade Vardarli*1

$\ddot{O} z$

Anahtar Sözcükler

Sanal gerçeklik

Sanal gerçekliğin ruh sağlığı alanında kullanımı, bilgisayarlı modeller yoluyla insan algılarının yapay nesne ve yerlerle gerçekte varmışçasına değiştirilmesine dayalıdır. Sanal gerçeklik maruz bırakma terapisi, güvenli, ekonomik ve kontrol edilebilir bir yöntem olması nedeniyle tercih edilmektedir. Diğer yandan sanal gerçeklik uygulamalarının geliştirilmesinin karmaşıklığı, kullanılan donanımların yüksek maliyetli olması ve sanal gerçeklik kullanımının neden olduğu olası yan etkiler, bazı sınırlılıklara neden olmaktadır. $\mathrm{Bu}$ yan etkiler, özellikle çocuklarla yapılan sanal gerçeklik uygulamalarının görece daha geç başlamasına neden olmuștur. $\mathrm{Bu}$ derleme makalesi kapsamında hem yetișkinlerle hem de çocuklarla yürütülen çalışmalara yer verilmektedir. Bu makalede ilk olarak sanal gerçeklik maruz bırakma terapisinin ne olduğu açıklanmış, ardından sanal gerçeklik terapisi ile sıklıkla çalışılmış olan özgül fobiler, kapalı alan ve açık alan korkusu, sosyal fobi, travma sonrası stres bozukluğu, obsesif kompulsif bozukluk, dikkat eksikliği ve hiperaktivite bozukluğu ile otizmde kullanılan sanal gerçeklik temelli uygulamalar ele alınmıştır. Daha sonra sanal gerçeklik uygulamaları, etkililikleri, yararları, olası zararları ve sınırlılıkları açısından değerlendirilmiştir.
Sanal gerçeklik maruz

birakma terapisi

Sanal gerçeklik terapisi

Makale Hakkında

Gönderim Tarihi

Kabul Tarihi

19 Nisan 2021

Makale Türü

Derleme Makalesi

DOI: $10.12984 /$ egeefd. 807422
08 Ekim 2020

\section{A Technological Approach: Virtual Reality Exposure Therapy}

Abstract

The use of virtual reality in the field of mental health is based on the change of human perceptions with artificial objects and places as if they exist in reality through computerized models. Virtual reality exposure therapy emerges as a preferred method because of being safe, economic and controllable. On the other hand, the difficulty of developing virtual reality applications, high cost of the virtual reality hardware systems, and possible side effects of virtual reality causes some limitations. Virtual reality applications for children started relatively late because of these side effects. This review article includes studies conducted with both adults and children. This article aims to explain what virtual reality therapy is and how it has been used in the process of counseling specific phobias, agoraphobia, posttraumatic stress disorder, obsessive compulsive disorder, attention deficit disorder, and autism. Subsequently, virtual reality applications were evaluated in terms of effectiveness, benefits, potential harmful aspects, and limitations.
Keywords

Virtual reality Virtual reality exposure therapy

Virtual reality therapy

Article Info

Received

October 08, 2020

Accepted

April 19, 2021

Article Type

Review Paper

Attf: Vardarlı, B. (2021). Teknolojik bir yaklaşım: Sanal gerçeklik maruz bırakma terapisi. Ege Eğitim Dergisi, 22(1), 40-56. doi: 10.12984 /egeefd. 807422

* Sorumlu Yazar / Corresponding Author

1 D VR Çocuk Bilişim Teknolojileri ve Danışmanlık Ltd. Şti. Türkiye. badevardarli@hotmail.com 


\section{Extended Abstract}

This paper describes what virtual reality exposure therapy (VRET) is, its scope, effectiveness, benefits, and potentially harmful aspects. The use of virtual reality in mental health is based on changing human perceptions with artificial objects and places as if they existed through computerized models. Thus, the client faces the environment which is controlled and changed according to his needs. Unlike in vivo exposure and imaginal exposure, in virtual reality exposure, (in virtuo exposure) the client is exposed to the environment created in computer. This is a technology, which enables client to be exposed to a situation in fully controllable environment. The level of difficulty of exposure is chosen by the counselor.

Virtual environments provide the sense of existence in controllable conditions. In these controllable conditions, the person is able to interact with virtual environment. Thus, it is possible for a person with a fear of heights to look down from the top of a high building, and for a person with a fear of dogs to slowly face the dog approaching him. Virtual reality enables creation of virtual environments similar to the real life situations. Thus, the skills can be transferred to the counseling process. For example, it enables the observation and evaluation of the client's behavior in a subway in the counseling room. Presenting the desired situation as often as needed is possible. For example, creating a situation where the plane takes off 10 times in a row for someone with flight phobia, or allowing the elevator to move without stopping on any floor for five minutes can be created. Virtual reality makes it possible to repeat therapeutic goals such as coping with an anxious situation and relaxation as often as desired under necessary conditions. It also provides a personalized plan specific for the client.

Gutierrez (2002), states that virtual reality offers a higher level of privacy compared to in vivo exposure. Because it is possible for the person to be exposed to an anxious situation in the counseling room with virtual reality. A counselee who hesitates to use public transport does not need to be brought into this environment and react to stress in front of other people. Facing the situation where counseling is performed and only under the supervision of the expert, "getting on the subway" is reassuring and ensures the privacy of client. In addition, environments that are not often experienced in real life such as the moment of storm, take-off of a plane can be created as often as desired. This is especially helpful for clients with low imagination. Virtual reality therapy enables clients who avoid confronting the real situation or who have difficulty in visualizing the anxious situation to face their concerns in a controlled environment. Experiencing the stressful situation in counseling room ensures that the client is not seen by others while facing his fears, thus minimizing embarrassment (North, North, \& Coble, 1997a).

VRET was first used to treat post-traumatic stress disorder in war veterans. Over time, VRET was started to be used in the treatment of specific phobias, anxiety disorders, obsessive-compulsive disorder, alcohol and substance addiction. It is noteworthy that virtual reality therapy programs, were mostly designed for adults and they were treatment-oriented. By the time, VRET programs have started to be designed for young people and children for healing, improvement, and preventive purposes. In addition, various virtual reality programs have been designed for social skills development of children who lack social skills such as school anxiety, social anxiety, asperger, and autism diagnoses.

VRET has begun to be used in diagnosing as well as treating psychological disorders. Self-report scales are frequently used in research in the field of psychology. In self-report scales, it is possible for clients to evaluate their experiences retrospectively, so the data obtained from these scales are limited to what the client remembers about the problem. Unlike self-report scales, virtual reality applications allow symptoms to be reported while they are occurring. For example, a virtual classroom environment has been created in the diagnosis of attention deficit and hyperactivity disorder. It has been shown that distracting stimuli is less disturbing for undiagnosed children (Adams, Finn, Moes, Flannery \& Rizzo, 2009; Parson, Bowerly, Buckwalter, \& Rizzo 2007; Rizzo et al., 2000). In addition, this study is important because of providing the opportunity to observe children's difficulties and what kind of reactions they give. In addition, virtual reality applications also allow the measurement of the physiological responses of the client during the exposure. Thus, it is possible to evaluate the client's reactions in a multiple way (Othmer \& Kaiser, 2000; Yan et al., 2000).

Efficacy studies of VRET have been rapidly increasing. Studies comparing the effectiveness of in virtuo exposure and in vivo exposure methods have shown that VRET can be as effective as experiential exposure. Increase of smart phone and tablet applications for VRET are remarkable in recent years. These applications are in a form of homework or self-help practices, rather than treatment tools. VRET emerges as a preferred method because of being safe, economic, and controllable. The frequency and severity of the exposure can be adjusted, reproducible, and can be closed at any time, allowing the client to participate in the experience with less resistance, and it is a practical method for counselors. VRET provides the opportunity to re-experience the impossible repetitive experiences such as a war, an attack, and an earthquake. In addition, virtual reality applications allow measurement of the client's physiological responses during exposure.

The difficulty of developing virtual reality applications and the high cost of the virtual reality hardware systems causes a limitation in the use of virtual reality. In addition, very few studies focused on the possible negative sides 
of virtual reality. It is known that virtual reality may cause side effects such as dizziness, nausea, and eye fatigue. It is also known that side effects are more common in individuals prone to epileptic seizures. If the exposure lasts more than half an hour, possibility of having side effects increases. Also, moving head fast during VRET implementation and having asthma increases the risk of experiencing side effects.

In Turkey, virtual reality therapy applications and efficacy studies have recently started. Virtual reality applications for adults to threat flight anxiety, arachnophobia, fear of dog, and fear of heights have been developed. Also, applications to develop children's social skills exist (Vardarl1, 2020). It is believed that new applications on VRET and efficacy studies will contribute to the field of mental health counseling. 


\section{Giriş}

1965 yılından bu yana geliştirilen sanal gerçeklik sistemleri, birçok alanda kullanılmaya başlamıştır (Baker, 2008). Başta eğlence amaçlı kullanılmaya başlanan sanal gerçeklik teknolojisi, günümüzde eğitim, sağlık, turizm, tasarım, ticaret gibi çeşitli alanlarda kullanılmaktadır. "Sanal gerçeklik” kelimesi, insan algısını yanıltabilecek unsurların bilgisayar ortamında hazırlanmasıyla yapılan deneyleri tanımlamak için kullanılmıştır. Sanal gerçeklik ile kullanıcılar gerçekmiş hissi verilen, bilgisayarlar tarafından yaratılmış ortamlara maruz bırakılırlar. Sanal gerçeklik gözlükleri ve pozisyon izleyici aletlerin kullanımı ile kullanıcı, yaratılan bilgisayar ortamında istediği yere gidebilir, yürüyebilir ve baktığı doğrultuyu belirleyebilir (Bayraktar ve Kaleli, 2007). Kişinin yaratılan sanal ortamda var olma hissi ile gerçek hayattakine benzer kontrol edilebilir ortamlar yaratılır. Bu kontrol edilebilen ortamlarda kişinin çevre ile etkileşim halinde olması sağlanır. Böylece yükseklik korkusu olan birinin yüksek bir binanın tepesinden aşağıya bakması, köpek korkusu olan birinin kendisine yaklaşan köpekle yavaş yavaş yüz yüze gelebilmesi, yüksek bir binanın en üst katına çıkmadan ya da köpekle gerçek hayatta yüz yüze gelmeden mümkün olabilmektedir.

Sanal gerçekliğin ruh sağlığı alanında kullanımı, bilgisayarlı modeller yoluyla insan algılarının yapay nesne ve yerlerle gerçekte varmışçasına değiştirilmesine dayalıdır. Böylece danışanın korktuğu durumla, kontrol edilebilen ve ihtiyacına göre değiştirilebilen bir çevre aracılığıyla karşı karşıya gelmesi sağlanmaktadır. Buna bağlı olarak yaratılan çevrenin karmaşıklık düzeyi, uyaranların miktarı, zorluk düzeyi gibi özellikler, uzman tarafından kontrol edilebilmektedir(Emmelkamp, 2005). Ayrıca danışanlar görsel ve işitsel uyaranların etkisi ile motive olmaktadır. Bazı uygulamalarda danışanların avatarlarla etkileşim içinde bulunması ve danışana anında geribildirim sağlanması mümkün olmaktadır. Bu şekilde danışanın aktivitelere katılımının arttırılması hedeflenir (Romano, 2005).

Sanal gerçeklik, terapide ilk kez savaş gazilerinde travma sonrası stres bozukluğunun tedavisinde kullanılmış, Irak Savaşı gazilerinin tedavisinde kullanımı ile devam etmiştir. Zamanla anksiyete bozukluklarının tedavisi, obsesif kompulsif bozukluk, dikkat eksikliği ve hiperaktivite bozukluğu ile otizm tedavisi gibi çeşitli alanlarda da kullanılır olmuştur (Akdeniz, Ahçı ve Yumuşak, 2020; Baker, 2008; Demirci, 2018; Herbelin, 2005). Öncelikli olarak yetişkinlere yönelik olarak tasarlanan sanal gerçeklik terapisi programları, zamanla çocuklara yönelik olarak da tasarlanmaya başlamıştır. Okul fobisi (Maldonado, Neri, Calafell ve Salazar, 2009), sosyal fobi (DeRosier, Craig ve Sanchez, 2012; Parrish, Oxhandler, Duron, Swank veBordnick, 2016; Sarver, Beidel ve Spitalnick, 2014; ThienAnn ve Beidel, 2017), asperger ve otizm tedavilerine yönelik (Didehbani, Allen, Kandalaft, Krawczyk ve Chapman, 2016; Ke ve Lee, 2016; Lorenzo, Lledo, Poares ve Roig, 2016)olduğu kadar sosyal becerilerde eksiklik yaşayan çocukların beceri gelişimine yönelik olarak da (Sarver, Beidel ve Spitalnick, 2014; Vardarl1, 2020) çeşitli sanal gerçeklik programları hazırlanmıştır.

$\mathrm{Bu}$ derleme makalesi kapsamında öncelikle sanal gerçeklik maruz bırakma terapisinin ne olduğu açıklanmış, ardından sanal gerçeklik terapisi ile sıklıkla çalışılmış olan özgül fobiler, kapalı alan ve açık alan korkusu, sosyal fobi, travma sonrası stres bozukluğu, obsesif kompulsif bozukluk, otizm ile dikkat eksikliği ve hiperaktivite bozukluğunda kullanılan sanal gerçeklik temelli uygulamalar ele alınmıştır. Daha sonra, sanal gerçeklik uygulamaları etkililikleri, yararları, olası zararları ve sınırlılıkları açısından değerlendirilmiştir.

\section{Sanal Gerçeklik Maruz Bırakma Terapisi}

Fobilerin tedavi edilmesinde maruz bırakma terapisi, sıklıkla kullanılan bir yöntemdir. Genelde danışanın kaçınma davranışı gösterdiği uyaran ya onun hayal gücünde var olan ya da gerçek hayatta karşılaştığ bir şeydir. Bazı danışanlar kaygı yaratan ve kaçınılan uyaranı zihinlerinde canlandırmakta zorlanırlar ve gerçek yaşamda da bu uyaran ile karşı karşıya gelmekten yoğun biçimde kaçınırlar.

Yaşantısal maruz bırakmada (in vivo exposure) gerçek hayatta kaçınılan duruma maruz bırakma söz konusudur. Bir diğer maruz bırakma, zihinsel imgelemedir (imaginal exposure). Bu yöntem danışanın kaçındığı durumu zihninde canlandırmasına, o durumun hayalini kurmasına dayalıdır. Sanal gerçeklik maruz bırakma terapisinde ise (in virtuo exposure) danışan bilgisayar ortamında yaratılmış olan çevreye maruz bırakılır. Sanal gerçeklik maruz bırakma terapisinin etkili olabilmesi için danışanın yaratılan çevrenin içinde gerçekten bulunuyormuş gibi hissetmesi, maruz bırakılan ortamın fizyolojik belirtileri ortaya çıkaracak kadar kaygı yaratabiliyor olması ve gerçek hayat ortamı ile benzerlik gösteriyor olması önemlidir (Üzümcü, Akın, Nergiz, İnözü ve Çelikcan, 2018).

Sanal gerçeklik, gerçek duruma benzer ortamların psikolojik danışma sürecine aktarılmasını sağlar; örneğin danışanın metrodaki davranışlarının gözlemlenmesinin ve değerlendirilmesinin psikolojik danışmanın yapıldığ odada gerçekleşmesini mümkün kılar (Emmelkamp, 2005). İstenen durumun istenen sıklıkta sunulabilmesi, örneğin uçuş fobisi olan biri için arka arkaya on kez uçağın kalktığı durumun yaratılması ya da beş dakika boyunca hiçbir katta durmadan asansörün hareket etmesinin sağlanması gibi gerçek hayatta mümkün olmayacak durumlar yaratılabilmektedir. Endişeli bir durumla baş etme, gevşeme gibi terapötik hedeflerin istenen koşullarda istenen sıklıkta tekrar edilmesini mümkün kılar ve danışana özgü kişiselleştirilmiş bir plan yapılmasını sağlar (Romano, 
2005). Gutierrez (2002), sanal gerçekliğin gerçek maruz kalmaya kıyasla daha yüksek düzeyde gizlilik sunduğunu belirtmektedir. Çünkü sanal gerçeklik sayesinde psikolojik danışmanın yapıldığı odada, kişinin kaygı verici duruma maruz bırakılması mümkündür. Toplu taşıma kullanmaktan çekinen bir danışanın bu ortama sokulması ve stres tepkilerini başka insanların önünde vermesi gerekmez. Psikolojik danışmanın yapıldığı alanda ve sadece uzmanın gözetiminde kaçınılan durumla yüzleşmek, örneğin "metroya binmek" güven vericidir ve danışanın gizliliğini korur. Ayrıca firtına anı, uçağın kalkışı gibi gerçek hayatta deneyimlenmesi sık olmayan ortamlar istenen sıklıkta yaratılabilmektedir. Bu durum özellikle hayal gücü az olan danışanlar için kolaylaştırıcıdır (North, North ve Coble, 1997a).Sanal gerçeklik terapisi gerçek durumla yüzleşmekten kaçınan ya da kaygı veren durumu zihninde canlandırmada zorlanan danışanların, kontrollü bir ortamda kaygıları ile yüzleşmelerini sağlar. Terapinin özel bir odada yapılıyor olması, danışanın korkuları ile yüzleşirken başkaları tarafından görülmemesini sağlar; böylece utanma en aza indirgenmiş olur.

Sanal gerçeklik terapisi yaşantısal maruz bırakmadan daha güvenli, ekonomik ve kontrol edilebilir olması açısından daha tercih edilebilir bir yöntem olarak ortaya çıkmaktadır (Emmelkamp, 2005; Romano, 2005). Maruz bırakmanın sıklığının ve şiddetinin ayarlanabilir olması, maruz bırakmanın tekrarlanabilir olması ve istendiği zaman kapatılabilir olması, hem danışanın daha az direnç göstererek deneyime katılmasını hem de uygulayıcı için yöntemin pratik olmasını sağlar (Valmaggia, Latif, Kempton ve Calafell, 2016). Ayrıca ortamın istenen koşullara göre düzenlenebilir olması, yani gündüz mü akşam mı olacağı, havanın güneşli mi yoksa yağmurlu mu olacağı gibi değişikliklerin yapılabilmesi, danışanın ihtiyacına uygun olan ortamın sunulmasını sağlar. Danışan, olayların gerçek hayatta gerçekleşmesini beklemek zorunda olmadığından, ancak istediği zaman onları üretip çoğaltabildiğinden, öğrenme sürecini hızlandırır (Emmelkamp, 2005). Örneğin, sanal gerçeklikle uçuş fobisi olan danışanın arka arkaya uçağın kalktığı anı yaşaması sağlanabilmektedir. Ayrıca psikolojik danışmanın danışanın gördüklerini bilgisayar ortamından izleyebilmesi, danışanın tepkilerini daha iyi gözlemlemesini sağlar (Gutierrez, 2002). Sanal gerçeklik maruz bırakma terapisinin bahsedilen yönleri ile pratik ve tercih edilen bir müdahale yöntemi olduğu düşünülmektedir.

Bilindiği kadarıyla sanal gerçeklik teknolojisinin psikolojik rahatsılıkların tedavisinde kullanılması ilk kez Atlanta Üniversitesinde yürütülen bir çalışma ile 1992 yılında gerçekleştirilmiştir ve o zamandan itibaren öncelikle uçuş korkusu, karanlık korkusu, hayvan korkusu, topluluk önünde konuşma korkusu gibi ağırlıklı olarak özgül fobilerin tedavisine yönelik programların geliştirilmesi ile hız kazanmıştır (North ve diğ. 1997a; North, North ve Coble, 1997b). Teknolojideki hızlı gelişmelerle beraber sanal gerçekliğin terapide kullanımı yaygınlaşmıştır ve geliştirilen programlarda avatarların da kullanılması ile sanal gerçeklik otizm, obsesif kompulsif bozukluk, sosyal fobi gibi farklı bozuklukların tedavisinde de kullanılan bir yöntem hâline gelmiştir.

\section{Özgül Fobi}

Özgül fobi, belirli bir duruma ya da nesneye karşı duyulan aşırı ve mantık dışı korkunun, bireyin günlük yaşamını olumsuz yönde etkilemesi durumudur (American Psychology Association [APA],2013). Sanal gerçeklik maruz bırakma terapisinde sıklıkla özgül fobiler çalışılmıştır ve bu alanda yapılan çeşitli meta analiz çalışmaları da sanal gerçeklik uygulamalarını özgül fobilerin tedavisinde etkili olduğunu ortaya koymaktadır (Parsons ve Rizzo, 2008; Powers ve Emmelkamp, 2008). Bu kısımda özgül fobi başlığı altında yükseklik fobisi, uçuş fobisi, hayvan fobisi ve sürüş fobisine yönelik yürütülen sanal gerçeklik çalışmalarına yer verilmektedir.

Yükseklik Fobisi (Akrofobi). Sanal gerçekliğe dayalı en çok çalışılan fobilerden biri yükseklik fobisidir. Bu alanda yapılan ilk çalışmalar sanal gerçeklik maruz bırakma terapisinin yükseklik fobisinin tedavisine yönelik hızlı sonuçlar verdiğini ortaya koymaktadır(North ve diğ. 1997b; Rothbaum ve diğ., 1995).

Yükseklik fobisinin tedavisinde sanal gerçeklik terapisinin kullanımına yönelik ilk çalışmalar, sanal gerçeklik terapisinin tek başına bir uygulama olarak etkili olup olmadığının araştırıldı̆̆ çalışmalardır (Rothbaum ve diğ. 1995). Ardından, yaşantısal maruz bırakma gibi geleneksel yöntemlere kıyasla etkililiği incelenmiş (Emmelkamp ve diğ., 2002) ve son yıllarda hem tedavi hem de önleyici amaçlarla geliştirilen daha kolay ulaşılabilir sanal gerçeklik sistemlerinin kullanıldı̆̆ uygulamaların etkililik çalışmaları yürütülmüştür (Donker, Esveld, Fischer ve Straten, 2018; Freeman ve diğ., 2018).

Rothbaum ve diğerleri(1995) yürüttükleri yedi haftalık sanal gerçeklik maruz bırakma tedavisine yönelik çalı̧mada, deney grubundaki üniversite öğrencilerine sanal gerçeklik maruz bırakma tedavisi grup uygulaması yapmış ve kontrol grubundaki öğrencilere herhangi bir müdahalede bulunmamışlardır. Deney grubuna farklı yüksekliklere ilişkin sanal çevrelerin bulunduğu aşamalı maruz bırakma uygulanmıştır ve zorlayıcı durumlara aşinalık geliştirmeleri amaçlanmıştır. Çalışmanın sonucunda deney grubunun kaygı düzeyinin kontrol grubuna göre anlamlı biçimde azaldığı bulunmuştur. Sanal gerçeklik maruz bırakma terapisi ile yaşantısal maruz bırakma tedavisinin karşılaştırıldığı başka bir çalışmada, sanal gerçeklik maruz bırakma terapisinin yaşantısal maruz bırakma tedavisi kadar etkili olduğu bulunmuştur (Emmelkamp ve diğ., 2002). Abdullah ve Shaikh (2018), yükseklik fobisi tanısı almış kişilerle yaptıkları çalışmada bir gruba sanal gerçeklik maruz bırakma terapisi uygularken diğer gruba gerçek maruz bırakma terapisi uygulamışlardır. Çalışmanın sonuçları, sanal gerçeklik 
maruz bırakma terapisi uygulanan grubun kaygı düzeyinin, gerçek maruz bırakma terapisi uygulanan gruba göre daha fazla azaldığını ortaya koymaktadır. Çelik, Alptekin ve Yavuz (2020) yükseklik fobisi tanısı almış iki kişiyle yürüttükleri altı haftalık programda kabul ve bağlılık terapisi ile sanal gerçeklik teknolojisini bir arada kullanmışlardır ve katılımcıların uygulama sonunda sanal çevrede beklenen davranışı gerçekleştirdikleri ve kaçınma tepkilerinin azaldığı ortaya konmuştur.

Sanal gerçeklik terapisinin yükseklik fobisinin tedavisinde kullanımının etkililiğinin test edildiği çalışmaların yanı sıra bazı çalışmalar, kullanılan donanımın tedavi üzerindeki etkisini araştırmaya yöneliktir. Diğer bir çalışmada ise kullanılan bilgisayar sistemlerinin terapinin etkililiği üzerindeki etkisi araştırılmıştır. İki farklı sanal gerçeklik teknolojisinin karşılaştırılmasını içeren çalışmada, pahalı ve temel iki sistem karşılaştırılmıştır ve bu ikisi arasında terapinin etkililiği açısından bir fark bulunmadığı ortaya konmuştur (Krijn ve diğ. 2004). Söz konusu çalışma, daha ulaşılabilir donanımlarla da sanal gerçeklik terapisinin uygulanabileceğini ve etkili sonuçlar elde edilebileceğini ortaya koyması açısından önemlidir. Başka bir çalışmada ise sanal koçun, uzman müdahalesinin ve kontrol grubunun kaygı düzeyleri çalışma öncesinde ve sonrasında karşılaştırılmıştır. İki haftada toplam altı oturumluk sanal gerçeklik maruz bırakma terapisi uygulanan deney grubu katılımcılarının bir grubu sanal koç ile diğer grubu ise gerçek terapist ile çalışmayı yürütmüşlerdir. Deney gruplarının kontrol grubuna göre hem uygulama sonrası hem de izleme sürecinde kaygı düzeylerinin azaldığı ortaya konmuştur. Bu çalışmada öncekilerden farklı olarak uygulama terapist gözetiminde yapılsa da danışan, programda oluşturulmuş sanal koç tarafından yönlendirilmiş̧ir. Çalışmanın klinik bulguları, uygulamanın gerçek terapist ile yüz yüze etkileşimde olduğu kadar etkili olduğunu ortaya koymaktadır (Freeman ve diğ. 2018). Son olarak, sanal gerçeklik maruz bırakma terapisinin ulaşılabilirliğini arttırmak amacı ile akıllı telefon kullanımına yönelik yükseklik fobisinin tedavisi için uygulama geliştirilmiştir ve uygulamanın etkililiğine ilişkin çalışmalar devam etmektedir (Donker ve diğ. 2018). Mevcut bulgular, sanal gerçeklik maruz bırakma terapisinin yükseklik fobisinin tedavisinde etkili bir yöntem olduğunu ortaya koymaktadır. Son yıllarda yapılan çalışmalar, mobil uygulamalar ya da avatar terapistlerin kullanımı ile uygulamaların maliyetini azaltmayı ve ulaşılabilirliğini arttırmayı hedeflemektedir.

Uçuş Fobisi. Uçuş fobisi olan kişiler uçağa binmek zorunda kaldıklarında uçağın düşeceğine, kaza olacağına dair şiddetli bir korku yaşarlar; uçağın her hareketi ve her sarsıntısı bu kişiler için aşırı biçimde korku vericidir. Uçuş fobisinin tedavisinin sanal gerçeklikle tedavisine dair yürütülen çalışmalar ilk olarak vaka çalışmaları ile başlamışıır. Yapılan ilk çalışmalar sanal gerçeklik maruz bırakma terapisinin tek başına bir yöntem olarak etkili olup olmadığını anlamaya yöneliktir (North ve diğ., 1997b; Rothbaum, Hodges, Watson ve Kessler, 1996). İlerleyen yıllarda yapılan çalışmalar ise gerçek maruz bırakma ve sanal gerçeklik maruz bırakma terapisinin etkililiğinin karşılaştırıldığı çalışmalardır (Rothbaum, Hodge ve Smith, 1999; Rothbaum ve diğ. 2006).

Rothbaum ve diğerleri (1996) uçuş fobisi olan bir kişiyle altı hafta yürütülen sanal gerçeklik maruz bırakma terapisi sonucunda danışanın kaygı düzeyinde anlamlı bir azalma olduğunu ortaya koymuşlardır. North ve diğerleri (1997a) tek katılımcı ile benzer bir çalışma yürütmüş ve benzer sonuçlar elde etmişlerdir. Her iki çalışmada da benzer bir yol izlenmiştir: Zihinde canlandırma ve gevşeme egzersizleri gibi kaygı azaltma yöntemleri kullanılmış, ardından katılımcı sanal gerçeklik uygulamasına maruz bırakılmıştır. Gerçek maruz bırakma terapisi ile sanal gerçeklik maruz bırakma terapisinin etkililiğinin karşılaştırıldığı bir diğer araştırmada ise her iki yöntemin de etkili olduğu ortaya konmuştur (Rothbaum ve diğ., 1999). Rothbaum ve diğerleri (2006), iki yöntemin etkililiğini karşılaştırdıkları başka bir araştırmada da benzer bir sonuç elde etmişlerdir ve iki yöntemin etkililiğinin altı ve on iki ay sonrasında alınan kalıcılık ölçümlerinde de benzer nitelikte olduğunu bulmuşlardır. Cardoş, David ve David (2018), yürüttükleri meta analiz çalışmasında, sanal gerçeklik ile yaşantısal maruz bırakmanın etkililik düzeylerinde fark olmadığını, ancak sanal gerçeklik maruz bırakma tedavisinin güvenli, kontrollü ve uygulanabilirliğinin daha pratik ve daha ekonomik bir yöntem olduğuna değinmişlerdir.

Yapılan çalışmalar uçuş fobisinin tedavisinde sanal gerçeklik terapisinin etkili bir yöntem olduğunu göstermektedir. Teknolojinin gelişmesi ve sanal gerçeklik programlarına ve donanımlarına ulaşılabilirliğin artması ile bu tedavi yönteminin klasik tedaviye göre daha ekonomik bir yöntem olacağı öngörülmektedir.

Hayvan Fobisi. Hayvan fobisi, özgül bir hayvanla ilgili belirgin bir korku ya da kaygı duyma durumudur (APA, 2013). Hayvanlara yönelik fobilerin tedavisinde sanal gerçeklik terapisi sık kullanılan bir yöntemdir. Hayvan fobisi çoğunlukla böceklere yöneliktir. Hayvan fobisinin tedavisinde yaşantısal maruz bırakma kısa sürede etkili sonuçlar verirken, aktif imgeleme yoluyla maruz bırakmanın aynı etkililikte olmadığı bilinmektedir. Ancak, yaşantısal maruz bırakma çok stresli bir yöntem olduğundan bazı danışanlar bu yöntemi tercih etmemektedir (Bouchard, Cote, St-Jacques, Robillard ve Renaud, 2006). Sanal gerçeklik terapisi hem gerçeğe yakın çevresel koşulların sağlanması hem de yaşantısal maruz bırakma kadar stres verici olmaması nedeni ile alternatif bir yöntem olmuştur.

Palacios, Hoffman, Carlin, Furness ve Botella (2002) geliştirdikleri uygulamada önce uzakta olan, sonra gitgide yakınlaşan örümceğe katılımcıları maruz bırakmışlardır; son olarak katılımcının örümceğe dokunması aşamasına kadar ilerlemişlerdir. Yaptıkları çalışmada sanal gerçeklik maruz bırakma terapisinin örümcek fobisinin 
tedavisinde etkili bir yöntem olduğunu ortaya koymuşlardır. Benzer biçimde, daha ekonomik olması yönünden bir bilgisayar oyununda düzenlemeler yapılarak sanal gerçeklik programı geliştirilmiştir ve uygulamanın örümcek fobisinin tedavisinde etkili bir yöntem olduğu ortaya konmuştur (Bouchard ve diğ. 2005). Taffou, Guerchouche, Drettakis, Viaud-Delman (2013) köpek korkusuna yönelik geliştirdikleri sanal gerçeklik uygulamasında sanal gerçekliğin hangi koşullarda daha gerçekçi etki yarattığını araştırmışlardır ve sadece görsel ya da sadece işitsel uyaran yerine iki uyaranın aynı anda kullanılmasının daha etkili olduğunu ortaya koymuşlardır. Işıklı, Baran ve Aslan (2019), özgül fobi tanısı almıș katılımcılarla yürüttükleri çalıșmada, köpek ve örümcek fobisi olan katılımcıların sanal gerçeklik senaryolarına aşamalı biçimde maruz bırakılmalarının ardından katılımcıların korku tepkilerinin azaldığını ortaya koymuşlardır. Bahsedilen örneklerden de anlaşılacağı üzere, sanal gerçeklik uygulamalarının hayvan fobilerinin tedavisinde hızla geliştiği görülmektedir.

Sürü̧s Fobisi. Sürüş fobisi yaygın karşılaşılan bir durum olmasına karşın, diğer özgül fobilere kıyasla tedavisinde sanal gerçeklik programlarının kullanılması bakımından daha az çalışılan bir alan olmuştur. Sanal gerçeklik maruz bırakma terapisi ile farklı sürüş koşullarını (günlük sürüş, yağmurlu havada, karlı havada sürüş vb.) risk almadan denemek mümkün olabilmektedir. Wald (2004) yaptığı çalışmada katılımcıları her biri üç beş dakika süren altı farklı senaryoya maruz bırakmıştır ve beş katılımcıdan üç tanesinin semptomlarında azalma olduğunu ortaya koymuştur. Costa, Carvalho, Ribeiro ve Nardi (2010), bu alanda yapılan çalışmaları inceledikleri meta analiz araştırmasında, sanal gerçekliğin sürüş fobisi için etkili bir yöntem olabileceğini ancak sanal gerçeklik uygulamasından sonra yaşantısal maruz bırakmanın kullanılmasının da tedavinin daha etkili olmasını sağlayacağını belirtmişlerdir. Bu görüşün temel nedeni sanal gerçeklikle katılımcıyı görsel ve işitsel uyaranlara maruz bırakmak mümkün olsa da sarsıntı, rüzgâr vb. diğer duyusal uyaranların yeterince kullanılamamasıdır. Benzer biçimde Costa ve diğerleri (2010), sekiz kadınla yürüttükleri deneysel çalışmada sürüş fobisinin tedavisinde sanal gerçeklik maruz bırakma terapisinin tek başına yeterli olmadığını belirtmişlerdir. Genel olarak bu alanda yapılan çalışmaların sayısının az olması, daha kesin yargılara varabilmek için bu alanda daha fazla kontrollü çalışmaya ihtiyaç duyulduğunu göstermektedir.

\section{Klostrofobi ve Agorafobi (Kapalı Alan Korkusu ve Açık Alan Korkusu)}

Klostrofobi; asansör, toplu ulaşım araçları, altgeçitler, alçak tavanlı mekânlar gibi kapalı ve basık yerlerden korkma durumudur. Klostrofobisi olan kişiler temelde, bulunulan yerde sıkışıp kalma, nefes alamama, o yerden çıkamama gibi durumlardan korkarlar (Botella ve diğ., 1998). Bu kişiler genellikle sinema ve tiyatroya gittiklerinde rahat hissedemezler; yakası kapalı-boğazlı giysilerle rahat edemezler ve kapalı havalarda kendilerini huzursuz hissederler. Agorafobisi olan kişiler ise evi terk etmekten ve toplumla teması gerektiren kalabalık ortamlara girmekten kaçınırlar. Klostrofobiye benzer biçimde sıkışı, dar, kalabalık ortamlara girmekten rahatsız olurlar (Üzümcü ve diğ., 2018). Klostrofobi ve agorafobinin tedavisi için kullanılan sanal ortamlar dar, sıkışık, kalabalık ortamları içermektedir. Yöntemin ve kullanılan ortamın benzer olması nedeniyle sanal gerçeklik maruz bırakma tedavisinde bu iki rahatsızlığa yönelik yapılan çalışmalar birlikte ele alınmıştır (Botella ve diğ., 1998; Malbos, Mestre, Note ve Gellato, 2008; Üzümcü ve diğ., 2018).

Klostrofobinin sanal gerçeklikle tedavisine yönelik yapılan ilk çalışmalar, vaka çalışmalarıdır. Yapılan ilk vaka çalışmaları danışanın kaygı verici duruma aşamalı biçimde maruz bırakılmasına dayalıdır (Botella ve diğ., 1998; Botella ve diğ., 1999). Başka bir çalışmadaysa bilinen bir oyunda kullanılan mekânlar, klostrofobinin tedavisinde kullanılmıştır (Malbos ve diğ., 2008). Kullanılan sanal gerçeklik sisteminin kalitesinin sonuçlara etkisinin araştırıldığı bu çalışmada, basit sanal gerçeklik donanımları ile etkili sonuçlar elde edilebileceği ortaya konmuştur (Bruce ve Regenbrect, 2009).

Botella ve diğerleri (1998) sanal gerçeklikle kapalı alan korkusunu tedaviye yönelik yürüttükleri vaka çalışmasında, katılımcıyı bir oda ve bir asansöre aşamaları zorlaşacak biçimde maruz bırakmışlardır. Yürütülen başka bir vaka çalışmasında da benzer bir yöntem kullanılmıştır (Botella, Villa, Banos, Perpina ve Palacious, 1999). Yapılan bu çalışmalarda katılımcıların kaygı ve kaçınma düzeylerinde anlamlı düşüş gözlendiği ve uygulamadan üç ay sonra da değişikliklerin sürdürüldüğü bulunmuştur. Asansörler, tüneller, mağaralar gibi mekânlar içeren "Game of the Year Edition" oyunun dönüştürülerek sanal gerçeklik mekânlarının yaratıldı̆̆ı başka bir çalışmada, ev ödevlerine de yer verilmiştir ve kullanılan yöntemin etkili olduğu bulunmuştur (Malbos ve diğ., 2008). Bruce ve Regenbrecht (2009), kullanılan sistemin kalitesinin uygulamanın etkililiği üzerindeki etkisini araştırmışlardır ve yaptıkları çalışmada çok donanımlı olmayan bilgisayar sistemlerinin kullanımının da sanal gerçeklik terapisinin etkililiğini azaltmadığını ortaya koymuşlardır.

Agorafobinin sanal gerçeklikle tedavisine yönelik olarak yapılan çalışmalarda alışveriş merkezi, ev, yol, otobüs, banka, tünel gibi mekânlar kullanılmıştır (Botella, Palacious, Villa ve Quero, 2004; Martin, Botella, Palacious ve Osma, 2007) Yapılan etkililik araştırmalarında sanal gerçeklik maruz bırakma terapisi ile bilişsel davranışçı terapiden elde edilen sonuçlar karşılaştırılmıştır (Martin ve diğ, 2007; Penate ve diğ., 2008).

Açık alan korkusuna yönelik ilk çalışmalar, diğer fobilere görece geç başlamıştır. İlk olarak Botella ve diğerleri (2004), bilişsel davranış̧ı terapi programına entegre ettikleri sanal gerçeklik terapisi için alışveriş merkezi, ev, 
yol, otobüs, tünel gibi sanal ortamlar yaratmışlardır. Martin ve diğerleri (2007)ise, banka, alışveriş merkezi, otopark, havaalanı, plaj, otoban ve teleferik olmak üzere yedi farklı alanın kullanıldığı başka bir çalışmada, sadece bilişsel davranışçı terapi alan grupla sanal gerçeklik maruz bırakma tedavisinin uygulandığı gruptan elde edilen sonuçları karşılaştırmış ve her iki yöntemin benzer etkililikte olduğunu ortaya koymuşlardır. Bu çalışma daha az seansta sanal gerçekliğin aynı etkililiği ortaya koyduğunu göstermesi açısından önemlidir (Penate ve diğ., 2008). Wiederhold ve Wiederhold (2003), agorafobi tedavisinde sanal gerçeklik kullanımını tartıştığı makalesinde, sanal gerçeklik terapisinin istendiği zaman sonlandırılabilir olması, maruz kalmanın aşamalarının ihtiyaca göre belirlenebiliyor olması ve yaşantısal maruz bırakmadan kaçınan danışanlar için daha az kaygı verici bir yöntem olması yönüyle sanal gerçekliğin agorafobi tedavisinde tercih edildiğini belirtmişlerdir.

$\mathrm{Bu}$ alanda yapılan çalışmalar klostrofobinin ve agorafobinin tedavisinde sanal gerçeklik terapisinin etkili bir yöntem olduğunu ancak daha kapsamlı ve büyük örneklemle yapılacak çalışmalarla desteklenmesi gerektiğini göstermektedir.

\section{Sosyal Fobi}

Bireyin başkaları tarafindan değerlendirilebilecek olduğu toplumsal durumlardan belirgin bir kaygı duyması durumudur. Karşılıklı konuşma, yeni bir sosyal çevreye girme, başkalarının önünde konuşma yapma gibi durumlarda kişi olumsuz değerlendirileceğine inanarak olumsuz davranmaktan ya da kaygı duyduğuna ilişkin belirtiler göstermekten kaçınır (APA, 2013). Sanal gerçeklik maruz bırakma terapisi ile sosyal fobinin çalışılması, gerçekçi avatarların yaratılmaya başlanması ile yaygınlaşmıştır.

Sosyal fobinin tedavisinde sanal gerçekliğin kullanımına dayalı çalışmalar hem yetişkinler hem de çocuklar için yürütülmektedir. Yetişkinlerle yapılan çalışmalar; sanal gerçeklik maruz bırakma terapisi ile bilişsel davranışçı grup terapisinin etkililiklerinin karşılaştııılmasını (Klinger ve diğ., 2005), bilişsel davranışçı terapi ile sanal gerçeklik maruz bırakmanın bir arada kullanılmasını (Anderson, Zimand, Hodges ve Rothbaum, 2005; Yıldız, Gül ve Birçek, 2020) ve sanal gerçeklik maruz bırakma terapisinin tek başına bir yöntem olarak kullanılmasını (Herbert, Forman, Goetter, Corner ve Bradley, 2013) içermektedir. Çocuklarla yapılan çalışmalarda sosyal fobisi olan çocukların sosyal becerilerini geliştirmeye yönelik gerçek maruz bırakma ve sanal gerçeklik maruz bırakma yöntemlerinin etkililiği karşılaştırılmış ve her iki yöntemin de çocukların sosyal beceri gelişimini desteklediği ortaya konmuştur (ThienAnn ve Beidel, 2017). Parrish ve diğerleri (2016) sanal gerçeklik maruz bırakma tedavisini kullanarak katılımcıların sosyal becerilerini geliştirmeye yönelik bir çalışma yürütmüşler ve yürüttükleri çalışmanın, katılımcıların sosyal becerilerini arttırdığını ortaya koymuşlardır. Başka bir çalışmada ise sosyal etkinlik terapisi ile sanal gerçeklik maruz bırakma terapisi bir arada kullanılmış ve deney grubunun sosyal kaygı düzeyinde anlamlı bir azalma olduğu ortaya konmuştur (Sarver, Beidel ve Spitalnick, 2014). Kim ve diğerlerinin (2017) yürüttüğü çalışmada, akıllı telefonlarda kullanmaya yönelik geliştirilen sanal gerçeklik uygulaması, sosyal kaygıyı azaltmak amacıyla kendi kendine yardımı mümkün kılacak biçimde geliştirilmiş ve bunun etkililiği test edilmiş̧ir. Çalışmanın sonucunda sekiz haftalık kendi kendine yardım uygulamasının, katılımcıların sosyal anksiyete düzeylerinde azalma sağladığı ortaya konmuştur.

Klinger ve diğerleri (2005) akşam yemeği konuşması, topluluk önünde konuşma, bir başkasının bakış açısına meydan okuyan konuşma ve başkası tarafından izlenirken görevi yerine getirmeye yönelik yaratılan dört sanal gerçeklik ortamına katılımcıları maruz bırakmış ve sanal gerçeklik terapisinin bilişsel davranışçı grup terapisine göre daha etkili olduğunu ortaya koymuşlardır. Başka bir çalışmada ise sanal gerçeklik terapisinin sekiz oturumluk bilişsel davranış̧̧ı terapi programı ile kullanılmasının topluluk önünde konuşma kaygısının tedavisinde etkili bir yöntem olduğu bulunmuştur. Söz konusu çalışmada ilk dört oturum sırasında sosyal fobi ile baş etme yöntemleri katılımcılara öğretilmiş, sonraki dört oturumda ise katılımcıların, sanal gerçeklik ortamındaki senaryolarda öğrendiklerini pratik etmeleri sağlanmıştır (Anderson ve diğ., 2005). Yıldız ve diğerleri (2020), bilişsel davranışçı temelli terapinin ardından sanal izleyici önünde konuşmayı gerektiren sanal gerçeklik terapisini uyguladıkları vaka çalışmasında, sanal gerçekliğin sosyal fobi belirtilerinin azalmasına katkı sağlayabileceğini belirtmişlerdir. Kampmann, Emmelkamp ve Morina (2016), bilişsel davranışçı terapi ile sanal gerçeklik terapisinin etkililiğini karşılaştırdıkları meta analiz çalışmalarında, sosyal fobinin tedavisinde her iki yöntemin de etkili olduğu sonucuna ulaşmışlardır. Sanal bir dünyada yaşamayı ve diğer oyuncularla iletişim hâlinde olmayı mümkün kılan "Second life" oyununun değiştirilmiş hâlinin kullanıldığı başka bir çalışmada ise oyundaki iletişim gerektiren senaryolara maruz bırakılan katılımcılar, çalışmanın hem uygulama sürecinde hem de sonrasında yapılan kalııılık ölçümlerinde sosyal fobi belirtilerinin azaldığını belirtmişlerdir(Herbert ve diğ. 2013).

Sosyal fobinin tedavisinde sanal gerçeklik terapisinin kullanımı yetişkinlerle sınırlı kalmamıştır. Son yıllarda çocuklar için geliştirilen uygulamalar da dikkat çekmektedir. ThienAnn ve Beidel (2017) 7-14 yaş arasındaki sosyal kaygısı yüksek öğrencilerin sosyal becerilerini geliştirmek için oluşturdukları sanal gerçeklik uygulamasında farklı okul ortamları yaratarak bu ortamlarda öğrencilerin selamlaşma, sohbeti başlatma ve sürdürme, sorun çözme gibi becerilerini geliştirmeye yönelik sosyal durumlara maruz kalmalarına yönelik uygulamalar yapmışlardır. Araştırmanın kontrol grubundaki öğrenciler, gerçek durumlara maruz bırakılmıştır. 
Hem deney hem kontrol grubundaki öğrencilerin sosyal kaygı düzeyinde azalma görüldüğü ancak uzmanların sanal gerçeklik uygulamasının daha pratik ve uygulanmasının daha kolay olduğunu belirttikleri ortaya konmuştur. Parrish ve diğerleri (2016), sosyal kaygı bozukluğu tanısı almış ergenler üzerinde sanal gerçeklik maruz bırakma tedavisinin etkililiğini araştırmışlardır. Bir partiye katılma ve topluluk önünde konuşma durumlarına sanal gerçeklik ortamında maruz bırakılan bireylerin kaygı düzeylerinin zamanla azaldığı ortaya konmuştur. Sarver ve diğerleri (2014), 8-12 yaş aralığındaki sosyal kaygı bozukluğu tanısı almış çocuklarla yaptıkları çalışmada, öncelikli olarak çalışmaya katılan çocuklar için sosyal etkinlik terapisi uygulamış, ardından sanal gerçeklik uygulamalarını yürütmüşlerdir. Süreçte ebeveynlerden ve çocuklardan sanal gerçeklik uygulamasına ilişkin görüşleri alınmıştır ve çocuklar sanal ortamı yüksek kaliteli bir program olarak değerlendirirken, ebeveynler de sanal ortamdaki zenginleştirilmiş tedaviden memnun kaldıklarını belirtmişlerdir.

Yapılan bazı çalışmalar sosyal kaygıya yönelik sanal gerçeklik kullanımını yaygınlaştırmayı amaçlamaktadır. Kim ve diğerlerinin (2017) sosyal kaygı düzeyleri yüksek olan kişilere yönelik olarak geliştirmiş oldukları akıllı telefon sanal gerçeklik uygulamasında, sekiz adet kendi kendine eğitim oturumu planlanmıştır. Bu uygulamada okul, iş ve günlük hayata dair seçenekler vardır ve her bir seçeneğin farklı zorluk düzeylerinde senaryoları bulunmaktadır. Bireyler başarılı oldukça bir sonraki aşamaya geçmektedirler. Her bir aşamadaki başarı, göz kontağı kurma, yanıtın uzunluğu ve ses tonuna göre uygulama tarafından otomatik olarak hesaplanmaktadır ve yapılan çalışma, bu oranlarda anlamlı biçimde artış olduğunu ortaya koymuştur (Kim ve diğ. 2017). Yetişkinlerde sosyal kaygıyı ortadan kaldırmaya yönelik olarak sanal gerçeklik terapisinin kullanılması önceleri topluluk önünde konuşma gibi durumsal kaygılara yönelik olarak geliştirilmiş olsa da zamanla avatar ve ortamların çeşitlendirilmesi ile farklı sosyal fobilere yönelik olarak ve çocuklar üzerinde de kullanılmaya başlanmıştır Ayrıca mobil uygulamalar gibi daha ulaşılabilir uygulamaların üretilmeye başlanması, sosyal kaygının azaltılmasında kendi kendine yardıma yönelik sanal gerçeklik uygulamalarının artmasını sağlayacağını düşündürmektedir.

\section{Travma Sonrası Stres Bozukluğu}

Travma Sonrası Stres Bozukluğu (TSSB), doğrudan örseleyici bir olay yaşama veya başkalarının başına gelen olaylara tanıklık etme yoluyla, ölümle veya ağır yaralanma ile karşılaşma sonucunda gelişebilen, kişilerde yoğun korku, dehşet ve çaresizlik hissi uyandıran, travma ile ilgili olayı yineleyici bir biçimde yaşama ve travma ile ilişkili uyaranlardan kaçınma gibi birtakım belirtilere sahip olan bir bozukluktur(APA, 2013). Travmaya yol açan olayların tekrarlanmasının mümkün olmaması, zihinde canlandırılmasının ise çoğunlukla kaçınma nedeniyle tercih edilmemesi nedeniyle sanal gerçeklik uygulamaları bu bozukluğun tedavisinde önemli bir alternatif olarak ortaya çıkmaktadır.

TSSB'nin sanal gerçeklik maruz bırakma terapisi ile çalışılması, vaka çalışmalarıyla başlamıştır. Rothbaum ve diğerleri (1999), Vietnam savaşına katılmış bir askerle yürüttükleri çalışmalarında, travmatik ortamı tetiklemek için biri helikopterlerin Vietnam üstünden uçtuğu bir anı gösteren, diğeriyse ormanda savaş anını gösteren iki senaryo tasarlamışlardır. Vietnam savaşına katılan askerlerle yapılan başka bir çalışmada katılımcıların belirtilerinde anlamlı biçimde bir azalma olduğu ortaya konmuştur (Rothbaum, Hodges, Ready, Graap ve Alarcon 2001). Başka bir vaka çalışmasında ise 11 Eylül saldırısı sonrası TTSB tanısı almış, aktif imgeleme ile maruz bırakmaya direnç gösteren bir katılımcı, patlama anına aşamalı olarak zorlaşan sanal ortamda maruz bırakılmıştır ve danışanın belirtilerinin uygulama sonrası azaldığı bulunmuştur (Difede ve Hoffman, 2004). Difede ve diğerleri (2007), 10 katılımcı ile yaptıkları deneysel çalışmada sanal gerçeklik terapisinin etkililiğine ilişkin benzer sonuçlar elde etmişlerdir. Irak ve Afganistan'dan dönen askerlerle yapılan çalışmalarda örneklem sayısı daha geniştir ve daha kontrollü çalışmalar yürütülmüştür. Beidel ve diğerleri (2017), Afganistan ve Irak Savaşı'na katılmış 92 askerle yaptıkları çalışmada, travmayla baş etme terapisi ile sanal gerçekliği ve psikoeğitim grubu ile sanal gerçekliği bir arada kullandıkları gruplardan elde edilen sonuçları karşılaştırmış ve her iki grupta da anlamlı farklılıklar olduğunu ortaya koymuşlardır. Schweitzer ve diğerleri (2018), TSSB tanısı almamış katılımcıların maruz bırakma sırasındaki stres düzeylerini ölçtükleri çalışmalarında, sanal gerçeklik maruz bırakma terapisi ile aktif imgeleme maruz bırakma tedavisinin gerçekçiliği arasındaki farkı incelemişlerdir. Her iki yöntemin de stres belirtilerini ortaya çıkardığını ancak sanal gerçeklikle maruz bırakmanın daha etkili olduğunu ortaya koymuşlardır. Yapılan çalışmalar sanal gerçekliğe dayalı uygulamaların TTSB'nin tedavisinde etkili bir yöntem olduğunu ortaya koymaktadır.

\section{Obsesif Kompulsif Bozukluk (OKB)}

Obsesif kompulsif bozukluğu olan kişiler, artan kaygıya neden olan müdahaleci, istenmeyen düşüncelerden kaynaklanan endişeyi azaltmak amacıyla tekrarlayıcı davranışları tecrübe ederler. Obsesyonlar zihinde beliren istem dışı düşünce, görüntü veya dürtüleri ifade ederken kompulsiyonlar, obsesyonların neden olduğu kaygıyı azaltmak amacıyla istemli olarak yapılan tekrarlayıcı davranışlardır (APA, 2013). Bilişsel davranışçı terapiye dayalı OKB tedavisinde, rahatsız edici duruma yaşantısal ya da imgeleme yoluyla maruz bırakma ile danışanın kompulsif davranışının engellenmesi söz konusudur. Ancak, yaşantısal maruz bırakma kaygı yaratıcı olduğundan, 
danışan bu yöntemi reddedebilmektedir. İmgeleme ile maruz bırakmada danışan rahatsızlık verici ortamı zihninde canlandirmakta zorlanabilmektedir (Rachman ve De Silva, 2009).

Yaşantısal ve imgeleme dayalı maruz bırakma yöntemlerine alternatif olarak sanal gerçeklik maruz bırakma terapisinin kullanılması, diğer bozuklukların sanal gerçeklikle terapisine kıyasla geç çalışılan bir alan olmuştur ve bu alanda çok fazla kontrollü çalışma yapılmamıştır (Kim, Kim, Kim, Roh ve Kim, 2009). Bu alanda yapılan çalışmaların terapinin etkililiğini değerlendirmekten çok, yaratılan sanal ortamın gerçekçi olup olmadığını test etmeye yönelik olduğu görülmektedir (Belloch ve di ̆. ., 2014; Kim ve diğ., 2008; Martine, Kasanmoentalib, Koning ve Denys, 2017).

OKB tanısı almış ve tanı almamış katılımcılarla yürütülen bir çalışmada, katılımcılar rahatsız edici sanal gerçeklik ortamlarına maruz bırakılmışlardır ve OKB tanısı almış grubun çalışmadan sonra daha çok kaygı ve stres yaşadığ ortaya konmuştur (Kim ve diğ., 2008). Belloch ve diğerleri (2014), OKB tanısı almış dört katılımcı ile yaptıkları çalışmada, sanal gerçeklik ortamının katılımcılar için gerçekçiliğini araştırmış ve katılımcıları sanal gerçeklik ortamındaki mutfakta rahatsızlık verici dört farklı aktivite içeren senaryoya maruz bırakmışlardır. Çalışmanın sonucunda sanal gerçeklik ortamının gerçekçi algılandığı, katılımcılarda kaygı ve tiksinme duygularını tetiklediği ortaya konmuştur. Martine ve diğerleri (2017), OKB tanısı almış 15 katılımcı ile yürüttükleri çalışmada, OKB semptomlarını ortaya çıkarmayı hedefleyen sanal gerçeklik oyununun, katılımcıların oyunu oynarken daha fazla semptom göstermelerine neden olduğunu ortaya koymuşlardır. Laforest, Bouchard, Bosse ve Mesly (2016), yürüttükleri pilot çalışmada OKB tanısı almış üç katılımcı ile bilişsel davranışçı terapi ve sanal gerçeklik maruz bırakma terapisini bir arada kullanmışlardır ve uygulamanın sonucunda katılımcıların semptomlarında azalma görüldügünü ortaya koymuşlardır. İnözü, Çelikcan, Akın ve Mustafaoğlu-Çiçek (2020), tiksinme ve korku tepkilerini azaltmayı amaçladıkları çalışmalarında, OKB tanısı almamış ancak korku düzeyi yüksek katılımcıların sanal gerçeklik uygulaması sonucunda kontrol grubuna göre daha az tiksinme ve kaygı tepkileri gösterdiklerini ortaya koymuşlardır. Çalışmalar, sanal gerçeklik maruz bırakma terapisinin gerçekçi ortamlar yaratma ve danışanların kaygı, tiksinti gibi duygularını tetiklemede etkili olduğunu ortaya koymaktadır. Ancak, terapinin etkililiğini test etmeye yönelik daha fazla kontrollü çalışmanın yapılmasına ihtiyaç olduğu görülmektedir.

\section{Dikkat Eksikliği ve Hiperaktivite Bozukluğu (DEHB)}

Dikkat Eksikliği ve Hiperaktivite Bozukluğu (DEHB), günlük görevleri ve rutinleri yerine getirmekte zorlanmaya neden olan, organizasyon güçlükleri, planlama ve plana uygun hareket etmede zorluklara neden olan, düşünmeden hareket etmenin sıkça görüldüğü bir durumdur (APA, 2013).

DEHB'de sanal gerçeklik teknolojisi iki amaçla kullanılmıştır: Bazı çalışmalar DEHB tanısı koyarken sanal gerçekliğin nasıl kullanılabileceğine odaklanırken (Adams, Finn, Moes, Flannery ve Rizzo, 2009; Parson, Bowerly, Buckwalter ve Rizzo, 2007; Rizzo ve diğ., 2000), bazı çalışmalar ise tedavide sanal gerçeklik kullanımının etkililiğini ortaya koymaya yöneliktir (Othmer ve Kaiser, 2000; Yan ve dĭg., 2008).

Rizzo ve diğerleri(2000),DEHB'in değerlendirilmesini amaçlayan sanal bir sınıf ortamı tasarlamışlardır. Dikkat dağıtıcı uyaranların olduğu bu sanal sınıfta, normal ve DEHB tanısı almış çocuklara odaklanma gerektiren görevler verilmiştir ve çocukların performanslarının değerlendirilmesi amaçlanmıştır. DEHB belirtilerini ölçmek için sanal sınıf ortamının kullanıldığı başka çalışmalarda da DEHB tanısı almış katılımcıların normal katılımcılara göre görevi yerine getirmekte zorlandıkları ve tanı almış katılımcılarda kaydedilen belirtilerin öz bildirim ölçeklerinde belirtilen belirtilerle tutarlı olduğu bulunmuştur (Adams ve diğ., 2009; Parsons, Bowerly, Buckwalter ve Rizzo, 2007).

Sanal gerçekliğin bir diğer kullanım alanı ise DEHB'in tedavisine yöneliktir. Neurofeedback uygulamasının sanal gerçeklik teknolojisi ile kullanımının etkililiğinin test edildiği bir araştırmada 120 katılımcı değerlendirilmiştir. Değerlendirmenin sonucunda tedavinin katılımcıların bilişsel performansını geliştirdiği ve sanal gerçekliğin normal neurofeedback uygulamasına göre daha çok fizyolojik aktivite yarattı̆̆ 2000). Yan ve diğerleri(2008), sanal gerçeklik ile neurofeedback uygulamasını birleştirdikleri çalışmalarında 20 oturumluk uygulamanın çocukların dikkatini geliştirdiğini bulmuşlardır. Yapılan çalışmalar, sanal gerçekliğin okul ortamında gözlenenden farklı sorunların değerlendirilmesi ve tedavisi için geçerli bir yöntem olduğunu göstermektedir. Ayrıca, sanal gerçekliğin değerlendirme ve tedavide kullanılmasının çocuklar için motive edici bir rolü olduğu belirtilmektedir (Pardo ve Garcia, 2012).

\section{Otizm}

Otizm, olağandışı toplumsal yaklaşıma, toplumsal etkileşime girmekte zorlanmaya ve kişiler arası paylaşımda bulunma konusunda eksikliklere neden olan bir iletişim bozukluğudur (APA,2013). Otizmin tedavisinde sanal gerçekliğin kullanılması, ilk olarak otizmde sıklıkla kullanılan kum havuzunun sanal gerçeklik ortamında yaratılması ile başlamıştır (Hirose, Kijiwa, Shirakawa, Nihei, 1997). Otizmli bireylerin sosyal becerilerini arttırmaya yönelik olarak tasarlanan bir çalışmada "sanal kafe" ortamı oluşturulmuş ve bu kafede otizmli bireylerin sağlıklı bireylerle iletişime geçerek sosyal becerilerini geliştirmelerini desteklemek hedeflenmiştir (Parsons, 
Mitchell ve Leonard, 2004). Sanal gerçeklikte avatarların kullanımının artmasıyla birlikte otizmde sosyal becerileri geliştirmeye yönelik olarak avatarlarla iletişime geçmeyi gerektiren uygulamalar üretilmeye başlanmıştır. Lorenzo ve diğerleri(2016), 7-12 yaş arası otizm tanısı almış çocukların sosyal becerilerini arttırmaya yönelik olarak geliştirdikleri sanal gerçeklik uygulamasında, çocukları farklı sosyal beceriler kullanmalarını gerektiren ortamlara maruz bırakmışlardır. Didehbani ve diğerleri (2016), 7-16 yaş arası otizm tanısı almış çocukların duygu düzenleme, sosyal katılım ve dikkat becerilerini arttırmaya yönelik olarak sanal gerçeklik uygulamasının etkililiğini test etmişlerdir. Uzmanın avatarlardan birini konuşturarak çocuğun tepkilerine yanıt verdiği bu uygulamada etkileşime dayalı bir ortam oluşturulmuştur ve uygulamanın çalışmaya katılan otizmli çocukların beceri gelişiminde etkili olduğu bulunmuştur. Otizmle ilgili yapılan sanal gerçeklik çalışmaları, özellikle sosyal beceri gelişimine katkısı yönünden umut vericidir.

Türkiye'de otizm açılımı kapsamında bozukluk tanısı almış bireylere bilgisayar destekli programlarla sosyal beceri eğitimi vermeye yönelik bazı programlar geliştirilmiştir. Sosyal beceri öğretiminde kullanılan sosyal öykülerin (Gray, 2004) bilgisayar ortamında tasarlanması ve öğrencilere geri sunulmasının etkililiğini araştıran bu çalışmalarda, sosyal öykülerin çocuklara bilgisayar ortamında verilmesine dayalı yöntemin etkililiği araştırılmıştır. Sosyal öykülerin bilgisayar ortamında sunulmasının çocukların sosyal beceri gelişiminde olumlu bir etki yarattığ ve tekrar tekrar uygulamayı mümkün kılması açısından pratik bir yöntem olduğu ortaya konmuştur (Bozkurt, 2016; Turan, 2015). Ancak, Türkiye'de henüz bu alanda sanal gerçekliğe dayalı bir program geliştirilmemiştir.

Genel olarak değerlendirildiğinde, sanal gerçekliğe dayalı maruz bırakma uygulamalarının, yükseklik fobisi, uçak fobisi, hayvan fobisi, kapalı alan korkusu, açık alan korkusu, sosyal fobi, travma sonrası stres bozukluğu, obsesif kompulsif bozukluk, dikkat eksikliği ve hiperaktivite bozukluğu ile otizm gibi rahatsılıkların tedavisinde kullanımın yaygınlaştığı ve bu alanda yapılan çalışmaların sürdüğü görülmektedir. Kontrol gruplarının ya da karşılaştırma gruplarının kullanıldığı çalışmalar, sanal gerçeklik maruz bırakma terapisinin etkililiğine işaret etmektedir.

\section{Sonuç ve Öneriler}

Sanal gerçeklik maruz bırakma terapisi, danışanların tamamen kontrol edilebilir ortamlarda, terapistin uygun gördüğü zorluk düzeyinde maruz bırakmayı mümkün kılan bir teknolojidir. Psikolojik rahatsızlıkları tedavi etmenin yanı sıra, tanı koymada da kullanılan sanal gerçeklik (Adams ve diğ., 2009; Parson ve diğ., 2006; Rizzo ve diğ., 2000), terapistin kontrolü altında danışanın sanal çevre üzerinden alışkanlık geliştirmesini ve baş etme becerilerini arttırmasını hedefler. Her ne kadar geçmişi 1990'lı yıllara dayanan görece yeni bir yöntem olsa da bu alanda yapılan çalışmaların sayısının gün geçtikçe arttığı ve farklı psikolojik rahatsılıkların tedavisinde kullanımının hızla yaygınlaştığı görülmektedir. Travma sonrası stres bozukluğu ve özgül fobilerin tedavisinde kullanılmaya başlayan sanal gerçeklik, zamanla uygulamalara avatarların da eklenmesi ile sosyal fobi, otizm, obsesif kompulsif bozukluk, dikkat eksikliği ve hiperaktivite bozukluğu gibi farklı psikolojik rahatsızlıkların tanı ve tedavisinde de kullanılmaya başlanmıştır.

Psikoloji alanındaki araştırmalarda öz bildirim ölçekleri sıklıkla kullanılır. Öz bildirim ölçeklerinde danışanların deneyimlerini geçmişe dönük olarak değerlendirmeleri söz konusudur; bu nedenle bu ölçeklerden elde edilen veriler danışanın probleme ilişkin hatırladıkları ile sınırlıdır. Sanal gerçeklik uygulamaları öz bildirim ölçeklerinden farklı olarak belirtilerin ortaya çıktığı anda raporlanmasını sağlar. Bu alanda dikkat eksikliği ve hiperaktivite bozukluğunun tanılanmasında sanal bir sınıf ortamı yaratılmıştır ve dikkat dağıtıcı uyaranların tanı almamış çocuklar için daha az rahatsız edici olduğu ortaya konmuştur (Adams ve diğ., 2009; Parson ve diğ., 2006; Rizzo ve diğ., 2000). Ayrıca yapılan bu çalışma, çocuğun özellikle hangi durumlarda zorlandığını ve ne gibi tepkiler verdiğini birebir gözlemleme imkânı sunması yönünden önemlidir. Üstelik sanal gerçeklik uygulamaları, maruz bırakma esnasında danışanın fizyolojik tepkilerinin ölçülmesine de imkân sağlar. Böylece danışanın tepkilerinin çok yönlü biçimde değerlendirilmesine olanak sağlanmış olur (Othmer ve Kaiser, 2000; Yan ve diğ., 2000).

Sanal gerçeklikle maruz bırakma ile yaşantısal maruz bırakma yöntemlerinin etkililiğinin karşılaştırıldığı bazı çalışmalar, sanal gerçeklik uygulamalarının yaşantısal maruz bırakma kadar etkili olabildiğini ortaya koymuştur (Cardoş ve diğ., 2017; Emmelkamp ve diğ., 2012; Rothbaum ve diğ., 1999; Rothbaum ve diğ., 2006). Ayrıca yaşantısal maruz bırakmaya direnç gösteren bazı danışanlar, daha kontrollü ve daha az riskli olduğu için sanal gerçeklik maruz bırakma yöntemine daha sıcak bakabilmektedir. Özellikle yaşantısal olarak maruz bırakmanın mümkün olmadığı savaş, kaza, deprem gibi durumlarda sanal ortamlar üzerinden maruz bırakma, önemli bir alternatif olarak ortaya çıkmaktadır. Ancak sanal gerçeklik uygulamalarının geliştirilmesi ve uygulamada kullanılan donanımın maliyetinin yüksek olması, sanal gerçekliğin kullanımda sınırlılığa neden olabilmektedir. Gerçek yaşam deneyimine benzer ortam sunan CAVE benzeri donanımlar, yüksek maliyetlidir. Sanal gerçeklik gözlüğünün kullanıldığı, bilgisayar ekranından danışanın maruz kaldığı ortamın takip edilebildiği ekipmanlar ise hem daha ulaşılabilir maliyettedir hem daha kolay taşınabilir (Romano, 2005) hem de son yıllarda bu ürünlerin çeşitli versiyonları piyasada daha kolay bulunabilmektedir. Bu alanda düşük ve yüksek maliyetli donanımlarla 
yapılan uygulamaların etkililiğinin karşılaştırıldığı araştırmalar, her iki yöntemin etkililik açısından anlamlı olarak farklılaşmadığını ortaya koymaktadır (Bruce ve Regenbrech, 2009; Krijn ve diğ., 2004).

Son zamanlarda sanal gerçeklik teknolojisinin bilgisayar ve akıllı telefonlarda kullanımının artması ile birlikte, tablet ve akıllı telefonlar üzerinden kullanılabilen sanal gerçeklik tedavisine yönelik uygulamaların da geliştirilmeye başlandığı dikkat çekmektedir (Donker ve diğ., 2018; Kim ve diğ., 2017). Bu uygulamalar tek başına bir tedavi olmaktan ziyade tedaviyi destekleyici ödevler ya da kendi kendine telkin uygulamaları olmaktadır. Bu gelişmeler, danışanlara verilen ev ödevlerinde sanal gerçekliğin kullanılması, uygulamalara ulaşılabilirliğin kolaylaşması ve tanı almamış kişilerce kullanılmasının yaygınlaşması ile tedaviden ziyade, önleyici çalışmalarda sanal gerçekliğin kullanılmasını arttırabilecektir. Yeni yapılan bazı çalışmaların ise yetişkinler ve çocuklarda farklı sosyal duygusal becerilerin geliştirilmesini amaçladığı dikkati çekmektedir. Buna bağlı olarak, psikolojik danışma alanında gerek önleyici koruyucu gerekse iyileştirici çalışmalar kapsamında kullanılmak üzere akademik, sosyal, duygusal pek çok farklı gelişim alanına ilişkin katkı sağlayacak sanal gerçeklik uygulamaları geliştirilebilir.

Sanal gerçeklik maruz bırakma terapisi yirmi yıldan uzun bir süredir psikolojik bozukluklar için bir tedavi seçeneği olarak ortaya çıkmıştır ve zaman, maliyet, uygulanabilirlik açılarından avantajlıdır. Ancak, bu konuda yapılan çalışmaların çok azı sanal gerçekliğin olası olumsuz özelliklerine odaklanmıştır. Sanal gerçekliğin terapide kullanıldığı ilk yıllarda özellikle şizofreni gibi gerçeklik algısında bozuklukların ortaya çıtığı rahatsızlıklar için bireylerin gerçeklik algısını bozabileceğine yönelik bir endişe olmuştur. Ancak TSSB'nin tedavisine yönelik yapılan çalışmalar haricinde maruz bırakmanın olası olumsuz etkilerinden bahsedilmemiştir (Fernandez-Alvarez ve diğ., 2018). Fiziksel olarak sanal gerçekliğin baş dönmesi, mide bulantısı, göz yorgunluğu gibi yan etkilere neden olduğu bilinmektedir (Chang, Kim ve Yoo, 2020). İnsan hareketlerinin bilgisayara aktarımında geçen süre, hareketle görüntünün tam olarak eş zamanlı olmamasına ve buna bağlı olarak baş dönmesi, mide bulantısı gibi istenmeyen yan etkilerin ortaya çıkmasına neden olabilmektedir (Bayraktar ve Kaleli, 2007). Ayrıca epileptik nöbetlere eğilimli kişilerde yan etkilerin daha fazla görüldüğü ve yarım saatten fazla süren maruz bırakmanın da yan etki olasılığını arttırdığı bilinmektedir (Romano, 2005). Bu nedenle uygulamanın 15-20 dakikayı geçmemesi ve uygulama esnasında danışanın ani baş hareketlerinden kaçınması önerilmektedir. Ayrıca danışan maruz kaldığı senaryoda oturur pozisyondaysa gerçekte de oturmalı, ayakta duruyorsa gerçekte de ayakta durmalıdır; uygulama esnasında masa, sandalye gibi bir şeye dokunuyor olmasının da yan etkileri azalttığı düşünülmektedir.

Sanal gerçekliğin olası yan etkileri konusunda yeterince çalışma yapılmamış olması ve belli bir süreden fazla kullanımın ne tür yan etkilere neden olabileceğinin bilinmesi, bu çalışmalara dahil edilecek olan bireylerin öncesinde detaylı tıbbi geçmiş öyküsünün alınması ve uygulamaların mümkün olduğunca kısa süreli olacak biçimde tasarlanması gibi önlemler almayı gerekli kılmaktadır.

Türkiye'de, sanal gerçeklik terapisi ile ilgili yayınlanan derleme çalışmaları (Akdeniz ve diğ., 2020; Özer ve Yöntem, 2019; Üzümcü ve dĭg., 2018) bulunmaktadır. Ayrıca özgül fobi tedavisine (Işıklı ve diğ., 2019), kapalı alan fobisine (Çelik ve diğ., 2020), tiksinme ve kaygı tepkilerinin azaltılmasına (İnözü ve diğ., 2020), sosyal kaçınma tepkilerinin azaltılmasına (Yıldız ve diğ., 2020) ve sosyal duygusal öğrenme becerilerinin desteklenmesine yönelik (Vardarl1, 2020) sanal gerçekliğin kullanıldığı etkililik çalışmaları yürütülmüştür. Henüz etkililik çalışmaları tamamlanmamış olan yetişkinlere yönelik uçuş korkusu, örümcek korkusu, köpek korkusu ile yükseklik korkusunu tedavi etmeye yönelik olarak TÜBİTAK desteği ile geliştirilmiş bir uygulama bulunmaktadır. Henüz geliştirilen uygulamanın etkililik çalışmalarına devam edildiği bilinmektedir. TÜBİTAK destekli benzer başka bir projede ise topluluk önünde konuşma korkusuna yönelik uygulamanın geliştirilmesi çalışmalarına devam edildiği bilinmektedir. Sosyal fobinin tedavisine yönelik geliştirilen başka bir uygulamada ise dokuz farklı sosyal ortamda danışanların uzman tarafından belirlediği avatar tepkilerine maruz kalmasına imkân sağlanmaktadır. Bu uygulamada avatarların söyleyecekleri ve kabul edici / nötr / reddedici gibi verecekleri tepkinin türü, uzman tarafından belirlenebilmektedir. Son olarak yine TÜBİTAK desteği ile geliştirilmiş olan başka bir uygulama, 8-12 yaş arasındaki çocukların sosyal-duygusal becerilerini geliştirmeye yöneliktir. Uygulamada, çocuğun farklı okul ortamlarına maruz bırakılarak farkındalığının arttırılması, iletişim ve baş etme becerilerinin arttırılması hedeflenmektedir. Bahsedilen son uygulama, yazar tarafından geliştirilmiştir. Geliştirilen uygulamaların kontrollü ortamlarda etkililiğinin test edilmesinin ruh sağlığ 1 alan yazınına ve bu alandaki uygulayıcılara büyük katkı sağlayacağı düşünülmektedir. 


\section{Kaynakça/References}

Abdullah, M., \& Shaikh, Z. A. (2018). An effective virtual reality-based remedy for acrophobia. International Journal of Advanced Computer Science and Applications, 9(6), 162-167. doi: 10.14569/IJACSA.2018.090623

Adams, R.,Finn, P., Moes, E., Flannery, K., \& Rizzo, A. (2009). Distractibility in Attention Deficit Hyperactivity Disorder (ADHD): The virtual reality classroom. Child Neuropsychology, 15(2), 120-135. doi: 10.1080/09297040802169077

Akdeniz, S., Ahçı, Z., \& Yumuşak, S. (2020). Sanal gerçeklik ve psikoterapide kullanımı. Karatay Sosyal Araştırmalar Dergisi, (4), 1-20.

American Psychological Association [APA]. (2013). Diagnostic and statistical manual of mental disorders (5th ed). Washington DC: American Psychiatric Association.

Anderson, P. L., Zimand, E., Hodges, L. F., \& Rothbaum, B. O. (2005) Cognitive behavioral therapy for publicspeaking anxiety using virtual reality for exposure. Depression and Anxiety, 22(3), 156-8. doi: $10.1002 /$ da. 20090

Baker, J. B. (2008). Using computer-based MUVES to develop social skills in elementary children: An exploratory study. (Unpublished doctoral dissertation). Regent University, America.

Bayraktar, E. ve Kaleli, F. (2007, Şubat). Sanal gerçeklik ve uygulama alanları. Akademik Bilişim'07 - IX. Akademik Bilişim Konferansı, Kütahya.

Beidel, D. C., Frueh, B. C., Neer, S. M., Bowers, C. A., Trachik, B., Uhde, W., \& Grubaugh, A. (2017). Trauma management therapy with virtual reality augmented exposure therapy for combat-related PTSD: A randomized controlled trial. Journal of Anxiety Disorders, 1-11. doi: 10.1016/j.janxdis.2017.08.005

Belloch, A., Cabedo, E., Carrió, C., Lozano-Quilis, J. A., Gil-Gómez, J. A., \& Gil-Gómez, H. (2014). Virtual reality exposure for OCD: Is it feasible? Revista de Psicopatología y Psicología Clínica, 19, 37-44.

Botella, C., Banos, R. M., Perpina, C., Villa, H., Alcaniz, M., \& Rey, A. (1998). Virtual reality treatment of claustrophobia: A case report. Behavior Research and Therapy, 36(2), 239-246. doi: 10.1016/S00057967(97)10006-7

Botella, C., Palacios, A., Villa, H., \& Quero, S. (2004). The use of VR in the treatment of panic disorders and agoraphobia. Studies in Health Technology and Informatics, 99, 73-90.

Botella, C., Villa, H., Banos, R., Perpina, C., \& Palacious, A. (1999). The treatment of claustroprohiba with virtual reality: Changes in other phobic behaviors not specifically treated. Cyber Psychology \& Behavior, 2(2), 135141. doi: $10.1089 / \mathrm{cpb} .1999 .2 .135$

Bouchard, S., Cote, S., St-Jacques, J., Robillard, G., \& Renaud, P. (2006). Effectiveness of virtual reality exposure in the treatment of anacarophobia using 3D games. Technology and Health Care, 14(2006), 19-27.

Bozkurt, S. S. (2016). Otizm spektrum bozukluğu olan çocuklara sosyal beceri öğretiminde teknoloji destekli etkileşimli ortam tasarımı ve etkililiği. (Yayımlanmamış doktora tezi). Anadolu Üniversitesi, Eskişehir, Türkiye.

Bruce, M., \& Regenbrecht, H. (2009). A virtual reality claustrophobia therapy system - implementation and test. In IEEE Virtual Reality Conference (pp. 19-25.), Washington: IEEE.

Cardoş, R. A. I., David, O. A., \& David, D. O. (2018). Virtual reality exposure therapy in flight anxiety: A quantitative meta-analysis. Computers in Human Behavior, 72(2017). 371-380. doi: 10.1016/j.chb.2017.03.007

Chang, E., Kim, H. T., \& Yoo, B. (2020). Virtual reality sickness: A review of causes and measurements. International Journal of Human-Computer Interaction, 36(17), 1658-1682. doi: $10.1080 / 10447318.2020 .1778351$ 
Costa, R. T., Carvalho, M. R., Ribeiro, P., \& Nardi, A. E. (2010). Virtual reality exposure therapy in the treatment of driving phobia. Psicologia: Teoria e Pesquisa, 26(1), 131-137. doi: 10.1590/S0102-37722010000100015

Çelik, Z., Alptekin, F. B., \& Yavuz, K. F. (2020). Acrophobia treatment with virtual reality assisted acceptance and commitment therapy: Case reports. Dusunen Adam The Journal of Psychiatry and Neurological Sciences, 33, 317-324. doi: 10.14744/DAJPNS.2020.00097

Demirci, Ş. (2018). Sağlık hizmetlerinde sanal gerçeklik teknolojileri. Inönü Üniversitesi Sağllk Hizmetleri Meslek Yüksekokulu Dergisi, 6(1), 35-46.

DeRosier, M. E., Craig, A. B., \& Sanchez, R. P. (2012). ZooU: A stealth approach to social skills assessment in schools. Advances in Human-Computer Interaction, 25, 1-7. doi: 10.1155/2012/654791

Didehbani, N., Allen, T., Kandalaft, M. Krawczyk, D., \& Chapman, S. (2016). Virtual reality social cognition training for children with high functioning autism. Computers in Human Behavior, 62, 703-711. doi: 10.1016/j.chb.2016.04.033

Difede, J., \& Hoffmann, H. J. (2004). Virtual reality exposure therapy for world trade center post-traumatic stress disorder: A case report. CyberPscyhology \& Behavior, 5(6), 529-535. doi: 10.1089/109493102321018169

Difede, J., Cukor, J., Jayasinghe, N., Patt, I., Jedel, S., Spielman, L., Giosan, C., \& Hoffman, H. G. (2007). Virtual reality exposure therapy for the treatment of posttraumatic stress disorder. Clinical Psychiatry Journal, $68(11), 1639-1647$

Donker, T., Esveld, S. V., Fischer, N., \& Straten, A. (2018). Phobia - towards a virtual cure for acrophobia: study protocol for a randomized controlled trial. Open Access, 19(433), 1-11.

Emmelkamp, P. M. (2005). Technological innovations in clinical assessment and psychotherapy. Psychotherapy and Psychosomatics, 74(6), 336-343, doi: 10.1159/000087780

Emmelkamp, P. M., Krijn, M., Hulsbosch A. M., Vries, S., Schuemie, M. J., \& Mast, C. A. (2002). Virtual reality treatment versus exposure in vivo: A comparative evaluation in acrophobia. Behaviour Research and Therapy, 40(2002), 509-516, doi: 10.1016/s0005-7967(01)00023-7

Fernandez-Alvarez, J., Rozental, A., Carlbring, P., Colombo, D., Riva, G., Anderson, P., Banos, R. M., Benbow, A., Bouchard, S., Breton-Lopez, J. M., Cardenaz, G., Difede, J., Emmelkamp, P., Garcia-Palacios, A., Guillen, V., Hoffman, H., Kampann, I., Moldovan, R., Mühlberger, A., North, M., Pauli, P., Penate-Castro, W., Quero, S., Tortella-Felui, M., Wyka, K., \& Botella, C. (2018). Deterioration rates in virtual reality therapy: An individual patient data level meta-analysis. Journal of Anxiety Disorders, 35(7), 34-43. doi: 10.1016/j.janxdis.2018.06.005

Freeman, D., Haselton, P., Freeman, J., Spanlang, B., Kishore, S., Albery, E., Denne, M., Brown, P., Slater, M., $\&$ Nickless, A. (2018). Automated psychological therapy using immersive virtual reality for treatment of fear of heights: a single-blind, parallel-group, randomized controlled trial. Lancet Psychiatry, 2018(5), 625-632, Doi: 10.1016/S2215-0366(18)30226-8

Gray, C. (2004). Social Stories 10.0: The new defining criteria and guidelines. The Jenison Autism Journal,16(1), $2-21$.

Gutierrez, J. (2002). Aplicaciones de la relidad virtual en pcilogia clinica. Aula Medica Psiquiatria, 4(2), 92-126.

Herbelin, B. (2005). Virtual reality exposure therapy for social phobia. (Unpublished doctoral dissertation). Université Louis Pasteur, Strasbourg, France.

Herbert, J. D., Forman, E. M., Goetter, E. M., Corner, R., \& Bradley, J. (2013). Treatment of social anxiety disorder using online virtual environments in second life. Behavior Therapy, 44(2013), 51-61. doi: 10.1016/j.beth.2012.06.001

Hirose, M., Kijima, R., Shirakawa, K., \& Nihei, K. (1997). Development of a virtual sand box: An application of virtual environment for psychological treatment. Studies of Health Technology Information. 44, 113-120. 
Işıklı, S., Baran, Z. ve Aslan, S. (2019). Özgül fobilerde sanal gerçeklik teknolojisi uygulamaları ile tedaviye yardımcı araç geliştirme: Bir etkililik çalışması. Klinik Psikiyatri, 22, 316-328. doi: 10.5505/kpd.2019.43660

İnözü, M., Çelikcan, U., Akın, B., \& Mustafaoğlu-Çiçek, N. (2020). The use of virtual reality exposure for reducing contamination fear and disgust: Can VR be an effective alternative exposure technique to in vivo? Journal of Obsessive Compulsive and Related Disorders, 25, 1-8. doi: 10.1016/j.jocrd.2020.100518

Kampmann, I. L., Emmelkamp, P. M. G., \& Morina, N. (2016). Meta-analysis of technology assisted interventions for social anxiety disorder. Journal of Anxiety Disorders. 42(2016), 71-84. doi: 10.1016/j.janxdis.2016.06.007

Ke, F., \& Lee, S. (2016). Virtual reality based collaborative design by children with high-functioning autism: Design-based flexibility, identity, and norm construction. Interactive Learning Environments, 24(7), 15111533. doi: $10.1080 / 10494820.2015 .1040421$

Kim, K., Kim, C. H., Kim, S. Y., Roh, D., \& Kim, S. (2009). Virtual reality for obsessive-compulsive disorder: Past and the future. Psychiatry Investigation, 6, 115-121. doi: 10.4306/pi.2009.6.3.115

Kim, K., Kim, C. H., Cha, K. R., Park, J., Han, K. \& Kim, Y. K. (2008). Anxiety provocation and measurement using virtual reality in patients with obsessive-compulsive disorder. Cyberpsychology Behavior, 11, 637-641. doi: $10.1089 / \mathrm{cpb} .2008 .0003$

Kim, H. E., Hong, Y., Kim, M., Jung, Y. H., Kyeong, S., \& Kim, J. (2017). Effectiveness of self-training using the mobile-based virtual reality program in patients with social anxiety disorder. Computers in Human Behavior, 73(2017), 614-619. doi: 10.1016/j.chb.2017.04.017

Klinger, E., Bouchard, S., Légeron, P., Roy, S., Lauer, F., \& Chemin, I. (2005). Virtual reality therapy versus cognitive behavior therapy for social phobia: A preliminary controlled study. Cyberpsychology and Behavior, 8(1),76-88. doi: $10.1089 / \mathrm{cpb} .2005 .8 .76$

Krijn, M., Emmelkamp, P. M. G., Biemond, R., Ligny, C., Schuemie, M. J., \& Mast C. A. (2004). Treatment of acrophobia in virtual reality: The role of immersion and presence. Behavior Therapy, 42, 229-239. doi: 10.1016/S0005-7967(03)00139-6

Laforest, M., Bouchard, S., Bosse, J., \& Mesly, O. (2016). Effectiveness of in virtuo exposure and response prevention treatment using cognitive behavioral therapy for obsessive disorder: A study based on a singlecase study protocol. Front Psychiatry, 13(7), 99. doi: 10.3389/fpsyt.2016.00099

Lorenzo, G., Lledo, A., Pomares, J., \& Roig, R. (2016). Design and application of an immersive virtual reality system to enhace emotional skills for children with autism spectrum disorders. Computers and Education, 98, 192-205. doi: 10.1016/j.compedu.2016.03.018

Malbos, E., Mestre, D. R., Note, I. D., \& Gellato, C. (2008). Virtual reality in claustrophobia: multiple components therapy involving game editor virtual environments exposure. Cyberpsychology and Behavior, 11, 695-697. doi: $10.1089 / \mathrm{cpb} .2007 .0246$

Maldonado, G. Z., Neri, E., Calafell, M., \& Salazar, C. P. (2009). Virtual reality exposure therapy for school phobia. Anuario de Psicología, 40(2), 223-236.

Martin, H. V., Botella, C., Palcios, A., \& Osma, J. (2007). Virtual reality exposure in the treatment of panic disorder with agoraphobia: A case study. Cognitive and Behavioral Practice,14(1), 58-69. doi: 10.1016/j.cbpra.2006.01.008

Martine, J. B., Kasanmoentalib, M. S., Koning, P. P., \& Denys, D. (2017). A virtual reality game to assess obsessive compulsive disorder. Cyber psychology, Behavior and Social Networking, 20(11), 718-722. doi: 10.1089/cyber.2017.0107

North, M. M., North, S. M., \& Coble, J. R. (1996). Virtual environment psychotherapy: A case study of fear of flying disorder. Teleoperators and Virtual Environments, 6(1), 127-132. doi: 10.1162/pres.1997.6.1.127 
North, M. M., North, S. M., \& Coble, J. R. (1997a). Virtual reality therapy: An effective treatment for psychological disorders. In Riva G. (Ed.), Virtual Reality in Neuro-Psycho-Physiology (pp. 59-65). Amsterdam, Netherlands: Ios Press.

North, M. M., North, S. M., \& Coble, J. R. (1997b). Virtual reality therapy for fear of flying. American Journal of Psychiatry, 154(1), 130-130. doi: 10.1176/ajp.154.1.130b

Othmer, S., \& Kaiser, D. (2000). Implementation of virtual reality in EEG biofeedback. Cyberpsychology \& Behavior, 3(3), 415-420. doi: 10.1089/10949310050078878

Özer, Ö. ve Yöntem, M. K. (2019). Sosyal anksiyeteye müdahalede teknolojik bir araç: Sanal gerçeklik. Psikiyatri Hemşireliği Dergisi, 10(4), 296-301. doi: 10.14744/phd.2019.75010

Palacios, A., Hoffman, H., Carlin, A., Furness, T. A., \& Botella, C. (2002). Virtual reality in the treatment of spider phobia: A controlled study. Behavior Research and Therapy, 40(9), 983-993. doi: 10.1016/s00057967(01)00068-7

Pardo, G. D., \& Garcia, I. M. (2012). Virtual reality applications in attention deficit disorder with hyperactivity: An approximation. Annuary of Clinical and Health Psychology, 2012(8), 29-37. doi: 10.2147/NDT.S206742

Parrish, D. E., Oxhandler, E. K., Duron, J. F., Swank, P., \& Bordnick, P. (2016). Feasibility of virtual reality environments for adolescent social anxiety disorder. Research on Social Work Practice, 26(7), 825-835. doi: $10.1177 / 1049731514568897$

Parsons, S., Mitchell, P., \& Leonard, A. (2004). The use and understanding of virtual environments by adolescents with autistic spectrum disorders. Journal of Autism and Developmental Disorders,34(4), 449-466. doi: 10.1023/B:JADD.0000037421.98517.8d

Parsons, T., \& Rizzo, A. (2008). Affective outcomes of virtual reality exposure therapy for anxiety and specific phobias: A meta-analysis. Journal of Behavior Therapy and Experimental Psychiatry, 39, 250-261. doi: 10.1016/j.jbtep.2007.07.007

Parsons, T., Bowerly, T., Buckwalter, J. G., \& Rizzo, A. (2007). A controlled clinical comparison of attention performance in children with ADHD in a virtual reality classroom compared to standard neuropsychological methods. Child Neuropsychology, 13(4),363-381. doi: 10.1080/13825580600943473

Penate, W., Fuente, J., Bethencourt-Pere, J. M., Acosta, L., Villaverde, M. L., \& Gracia, R. (2008). Agoraphobia: Combined treatment and virtual reality. Actas Esp Psiquiatr, 36(2), 94-101.

Powers, M. B., \& Emmelkamp, P. M. G. (2008). Virtual reality exposure therapy for anxiety disorders: A metaanalysis. Journal of Anxiety Disorders, 22, 561-569. doi: 10.1016/j.janxdis.2007.04.006

Rachman, S., De Silva, P. (2009). Obsessive compulsive disorder (4th ed.), New York: Oxford University Press.

Rizzo, A. A., Buckwalter, T. B., Zaag, V., Humphrey, L., Neumann, U., Chua, C., Kyriakakis, A, Van Rooyen, A., \& Sisemore, D. (2000). The virtual classroom: A virtual reality environment for the assessment and rehabilitation of attention deficits. Cyberpsychology \& Behavior, 3(3), 21-32. doi: $10.1089 / 10949310050078940$

Romano, D. M. (2005). Virtual reality therapy. Developmental Medicine and Child Neurology, 47, 580-580.

Rothbaum, B. O., Hodges, L. F., \& Smith, S. (1999). Virtual reality exposure therapy abbreviated treatment manual: Fear of flying application. Cognitive and Behavioral Practice, 6, 234-244. doi: 10.1016/S10777229(99)80081-9

Rothbaum, B. O., Hodges, L. F., Ready, D., Graap, K., \& Alarcon, R. D. (2001). Virtual reality exposure therapy for Vietnam veterans with posttraumatic stress disorder. The Journal of Clinical Psychiatry, 62(8), 617-622. doi: $10.4088 /$ jcp.v62n0808

Rothbaum, B. O., Hodges, L., Watson, B. A., \& Kessler, G. D. (1996). Virtual reality exposure therapy in the treatment of fear of flying: A case report. Behaviour Research and Therapy, 34(5), 477-481. 
Rothbaum, B. O., Hoges, L., Alarcon, R., Shahar, F., Graap, K., Pair, J., Hebert, P., Gotz, D., Wills, B., \& Baltzer, D. (1999). Virtual reality exposure therapy for PTSD Vietnam veterans: A case study. Journal of Traumatic Stress, 12(2), 262-271.

Rothbaum, B., Anderson, P., Zimand, E., Hodges, L., Lang, D., \& Wilson, J. (2006). Virtual reality exposure therapy and standard (in vivo) exposure therapy in the treatment of fear of flying. Behavior Therapy, 37, 8090. doi: 10.1016/j.beth.2005.04.004

Rothbaum, B., Hodges, L., Kooper, R., Opdykes, D., Williford, J., \& North, M. (1995). Effectiveness of computergenerated (virtual reality) graded exposure in the treatment of acrophobia. American Journal of Psychiatry, $152(4), 626-628$

Sarver, N. V., Beidel, D. C., \& Spitalnick, J. S. (2014). The feasibility and acceptability of virtual environments in the treatment of childhood social anxiety disorder. Journal of Clinical Child and Adolescent Pscychology, 43(1), 63-73. doi: 10.1080/15374416.2013.843461

Schweitzer, T., Renner, F., Sun, D., Kleim, B., Holmes, E. A., \& Tuschen-Caffier, B. (2018). Psychophysiological reactivity, coping behavior and intrusive memories upon multisensory Virtual Reality and Script Driven Imagery an alogue trauma: A randomized controlled crossover study. Journal of Anxiety Disorders, 59, 4252. doi: 10.1016/j.janxdis.2018.08.005

Taffou, M., Guerchouche, R., Drettakis, G., \& Viaud-Delmon, I. (2013). Auditory-visual aversive stimuli modul at the conscious experience of fear. Multisensory Research, 26(2013), 347-370.

Turan, C. (2015). Otizm spektrum bozukluğu gösteren çocuklara sosyal beceri ögretiminde sosyal öykü ve video model uygulamalarının etkililik ve verimlilikleri. (Yayımlanmamış doktora tezi). Anadolu Üniversitesi, Eskişehir, Türkiye.

Üzümcü, E., Akın, B., Nergiz, H., İnözü, M., \& Çelikcan, U. (2018). Anksiyete bozukluklarında sanal gerçeklik. Psikiyatride Güncel Yaklașımlar, 10(1), 99-117. doi: 10.18863/pgy.336593

Valmaggia, V. L., Latif, L., Kempton, M. J., \& Rus-Calafell, M. (2016). Virtual reality in the psychological treatment for mental health problems: An systematic review of recent evidence. Pschiatry Research, 236, 189-195. doi: 10.1016/j.psychres.2016.01.015

Vardarlı, B. (2020). Çocuklar için sanal gerçeklik sosyal duygusal ögrrenme becerileri ĕgitiminin tasarlanması ve etkililiğinin incelenmesi: Bir karma yöntem çallşması. (Yayımlanmamış doktora tezi). Ege Üniversitesi, İzmir, Türkiye.

Wald, J. (2004). Efficacy of virtual reality exposure therapy for driving phobia: A multiple baseline across-subjects design. Behavior Therapy, 35, 621-635.

Wiederhold, B. K., \& Wiederhold, M. D. (2003). Using virtual reality psychotherapy in panic disorder with agoraphobia. Pschriatric Times, 20(7), 45-51.

Yan, N., Wang, J., Liu, M., Zong, L., Jiao, Y., Yue, J., Lv, Y., Yang, Q., Lan, H., \& Liu, Z. (2008). Designing a brain computer interface device for neurofeedback using virtual environments. Journal of Medical and Biological Engineering, 28(3), 167-172.

Yıldız, B., Gül, E. ve Birçek, N. I. (2020). Bir sosyal fobi vakasında bilişsel davranışçı terapi ve sanal gerçeklik kombinasyonu. Bilişsel Davranışçı Psikoterapi ve Araştırmalar Dergisi, 9(2), 158-165. doi: 10.5455/JCBPR.61718 